\title{
Pseudo-equilibrium equation of calcium phosphate precipitation from aqueous solution
}

\author{
Hong-Xing Fan ${ }^{a, b}$, Bao-Di Gou ${ }^{c}, Y u-X i$ Gao ${ }^{a}$, Gang Wu ${ }^{b}$, Tian-Lan Zhang, ${ }^{c, *}$
}

* Fax: 86-10-62015584. Tel.: 86-10-82801539. E-mail: tlzhang@hsc.pku.edu.cn.

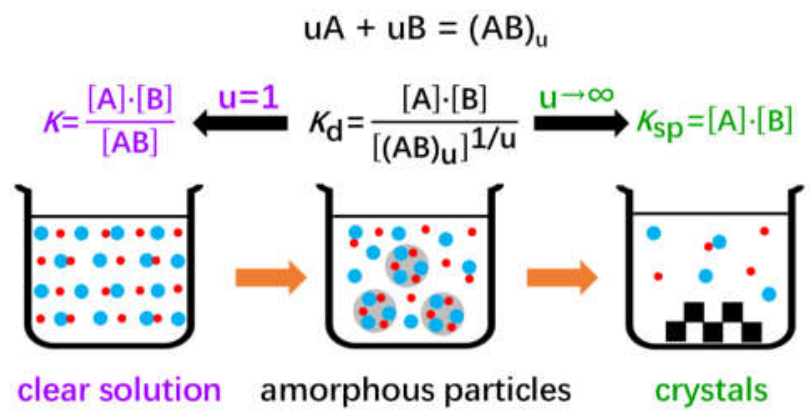

Texture matters. An amorphous phase is present at the early stage of calcium phosphate crystallization. In this case, the equilibrium constant equation takes the general form (middle). It converts to the conventional "reaction quotient" (left) and "solubility product" (right) in two limit cases, respectively. 


\title{
Pseudo-equilibrium equation of calcium phosphate precipitation
}

\section{from aqueous solution}

\author{
Hong-Xing Fan ${ }^{a, b}$, Bao-Di Gou ${ }^{c}, Y u-X i$ Gao ${ }^{a}$, Gang $W u^{b}$, Tian-Lan Zhang ${ }^{c, *}$
}

a. State Environmental Protection Engineering Center for Mercury Pollution Prevention and Control, Beijing Synchrotron Radiation Facility, Institute of High Energy Physics, Chinese Academy of Sciences, 19B Yuquan Road, Beijing 100049, P. R. China

b. Department of Biochemistry, Baotou Medical College, Inner Mongolia University of Science \& Technology, Baotou 014010, P. R. China

c. Department of Chemical Biology, Peking University School of Pharmaceutical Sciences. 38 Xueyuan Road, Beijing 100191 P. R. China.

ABSTRACT: An X-ray amorphous phase is frequently present at the early stage of calcium phosphate crystallization, and the relevant solution chemistry is essential for understanding the mechanism of reaction. Here, we report a quantitative study of a series of reaction systems at pseudo-equilibrium states. We determined the solution compositions and the quantities of the precipitate samples, and characterized the long- and short-range order of the precipitate using Xray diffraction and synchrotron X-ray absorption near-edge structure spectroscopy respectively. We found that, in a particle containing multiple structural units, only a fraction of the units was able to reach pseudo-equilibrium with the solution composition. This fraction, with its value being determined experimentally, represents the average number of surficial clusters per unit. These findings enabled us to propose a general form of equilibrium constant equation. The equation fits 
the pseudo-equilibrium data well, and it converts to the "solubility product $\left(K_{\mathrm{sp}}\right)$ " and conventional "reaction quotient" in two limit cases, respectively. Further, using a cube model, we derived a "particle equation" that reveals the connection between certain particle parameters and the equilibrium constant equation.

\section{INTRODUCTION}

Calcium phosphate crystals have invoked extensive and intensive studies, owing to their biological importance as the major inorganic constituents in bone and tooth enamel of vertebrates. In 1965, Eanes et al. reported an X-ray amorphous calcium phosphate (ACP). ${ }^{1}$ This substance is frequently present at the early stage of crystallization from near neutral solution..$^{2-4}$ In 1974, Betts and Posner detected a cluster structure in ACP, which had the atomic arrangement similar to a $\mathrm{Ca}_{9}(\mathrm{PO} 4)_{6}$ portion of hydroxyapatite $\left[\mathrm{Ca}_{10}(\mathrm{OH})_{2}\left(\mathrm{PO}_{4}\right)_{6}, \mathrm{HAP}\right]$ and, thus, made them to speculate that such clusters could be present in solution and compose ACP particles via aggregation..$^{5,6}$ Recent studies support the notion that ACP is the aggregated particles of solution clusters, ${ }^{7,8}$ but suggest that these clusters are more likely to be the smaller and structurally simple ones. ${ }^{9-11}$ By means of advanced experimental techniques ${ }^{12-15}$ and molecular modeling ${ }^{16-18}$, people are acquiring the structural information of these clusters in more detail.

In addition to the structural information, also essential is the quantitative solution chemistry of the reaction system containing ACP. However, the progress has relatively been slow in this field, as compared with the achievements in the exploration of ACP structure. ${ }^{15}$ A major difficulty arises from the metastability of ACP. Owing to its propensity towards crystallization, one cannot acquire the equilibrium data by extending reaction time. Nevertheless, early investigators tackled this problem by collecting pseudo-equilibrium data when the reaction proceeded at a low rate. In 1978, 
Meyer and Eanes obtained an invariant ion product for the amorphous calcium phosphate with a charge-neutral formula of $\mathrm{Ca}_{3}\left(\mathrm{PO}_{4}\right)_{1.87}\left(\mathrm{HPO}_{4}\right)_{0.2 .}{ }^{19}$ In 1986, Lundager Madsen et al. reported a "formation product" of ACP with the form of $\mathrm{I}_{\mathrm{a}}=\mathrm{a}^{3}\left(\mathrm{Ca}^{2+}\right) \mathrm{a}^{2}\left(\mathrm{HPO}_{4}{ }^{2-}\right) \mathrm{a}^{2}\left(\mathrm{H}^{+}\right)$, noting that is not "an equilibrium value like the solubility product, but rather a limit of metastability related to the critical supersaturation of some solid substance." ${ }^{20}$ In 1990, Christoffersen et al. reported the apparent solubility products for two types of ACP, both equivalent to $K=\left[\mathrm{Ca}^{2+}\right] \cdot\left[\mathrm{HPO}_{4}{ }^{2-}\right]^{0.74}$ $[\mathrm{H}]^{0.22} \cdot{ }^{21}$ In 2009 , Holt et al. reported the solubility product for a kind of protein-sequestered ACP, with the form $K_{\mathrm{S}}=a_{\mathrm{Ca}} \cdot a_{\mathrm{HPO} 4}^{y} \cdot a_{\mathrm{PO} 4}^{(2-2 y) / 3} \cdot 22$ To our knowledge, all the reported pseudoequilibrium equations of ACP take the form of "solubility product" or "ion activity product" $\left(K_{\mathrm{sp}}\right)$, with the activity of ACP assumed to be 1 .

But, given the much weaker inter-cluster bonding in ACP than in a crystalline phase, the amorphous phase would not be eligible for being assigned to the activity of 1 . In fact, we derived a formation constant that depends on both the solution composition and the amount of ACP in a preliminary study. ${ }^{8}$ Accordingly, the pseudo-equilibrium constant equation may not take the form of conventional "solubility product $\left(K_{\mathrm{sp}}\right)$ ". Hence the aim of the present study was to examine the relationship between the solution composition and the quantity of the precipitate. We collected pseudo-equilibrium samples from a series of reaction systems with different initial $\mathrm{Ca} / \mathrm{P}$ molar ratios, determined the solution compositions and the quantities of the precipitate samples. Further, we characterized the long- and short-range order of the precipitate samples using X-ray diffraction (XRD) and synchrotron X-ray absorption near-edge structure (XANES) spectroscopy respectively. We found that, in a structural unit of a sufficiently large and compact particle, only a fraction of it was able to reach pseudo-equilibrium with the solution composition. We determined the chemical composition of the fraction at various stages of reaction, and proposed a general form of 
equilibrium constant equation. This equation fits the pseudo-equilibrium data well, and it converts to the "solubility product $\left(K_{\mathrm{sp}}\right)$ " and conventional "reaction quotient" in two limit cases, respectively. Further, using a cube model, we derived a "particle equation" that reveals the connection between some parameters of multi-unit particles and the equilibrium constant equation.

\section{EXPERIMENTAL SECTION}

Materials and Solutions. $\mathrm{CaCl}_{2} \cdot 2 \mathrm{H}_{2} \mathrm{O}, \mathrm{Na}_{2} \mathrm{HPO}_{4}$, dicalcium phosphate dihydrate (DCPD, $\left.\mathrm{CaHPO}_{4} \cdot 2 \mathrm{H}_{2} \mathrm{O}\right)$, and hydroxyapatite $\left[\mathrm{HAP}, \mathrm{Ca}_{10}\left(\mathrm{PO}_{4}\right)_{6}(\mathrm{HO})_{2}\right]$ nanopowder were the products of Sigma-Aldrich (Saint Louis, Missouri, USA). The standard solutions for calibrating calcium and $\mathrm{pH}$ electrodes were from Mettler Toledo (Switzerland). High purity $\mathrm{HNO}_{3}$ was from Beijing Chemical Works (BV-III Grade, Beijing, China). Other reagents were of analytical grade.

Stock solutions of $\mathrm{CaCl}_{2}\left(20 \mathrm{mmol} / \mathrm{L}, \mathrm{pH}\right.$ 6.5-7.0) and $\mathrm{Na}_{2} \mathrm{HPO}_{4}(20 \mathrm{mmol} / \mathrm{L}, \mathrm{pH} 8.8)$ were freshly prepared with deionized water. The working solutions of $\mathrm{CaCl}_{2}$ and $\mathrm{Na}_{2} \mathrm{HPO}_{4}$ were prepared using the respective stock solutions, and passed through $100 \mathrm{~nm}$ pore-size syringe filters (Minisart $^{\circledR}$, Sartorium Stedim, Germany) before use.

Simultaneous Measurement of $\mathbf{p H}$ and Calcium Drifts. We mixed equal volumes of the thermostated working solutions in a $100-\mathrm{mL}$ beaker. The beaker was in a water-jacketed Pyrex cell kept at $25 \pm 0.2{ }^{\circ} \mathrm{C}$. The mixture in the beaker was magnetically stirred at the speed of $20 \%$ (instrument scale), and purged with argon gas (Ar 99.999\%, Huanyu Jinghui Co., China) purged with to reduce the effect of atmosphere $\mathrm{CO}_{2}$. The $\mathrm{Ca}^{2+}$ concentration and $\mathrm{pH}$ values were recorded at the frequency of $2 \mathrm{pts} / \mathrm{min}$ by a SevenExcellence ${ }^{\mathrm{TM}}$ instrument (Mettler Toledo, Switzerland). A 4-points calibration $(1,2,4,8 \mathrm{mmol} / \mathrm{L})$ for $\mathrm{Ca}^{2+}$ and a 3-points calibration for $\mathrm{pH}$ were performed immediately before each measurement. 
Sample Collection and Elemental Analyses. In a typical experiment, we drew $2 \mathrm{~mL}$ of suspension from the middle of the beaker at a scheduled time-point, and separated the supernatant and precipitate by centrifugation at $6000 \times \mathrm{g}$ for $5 \mathrm{~min}$ (HC-3018, Zhongjia Co, Anhui, China). After centrifugation, $0.2 \mathrm{~mL}$ of the supernatant was mixed with $0.8 \mathrm{~mL}$ of $3 \% \mathrm{HNO}_{3}$, and the $\mathrm{Ca}$ and $\mathrm{P}$ contents in the sample were determined, together with the diluted standard solution at the same level, by inductively coupled plasma optical emission spectrometry (ICP-OES) as described previously. ${ }^{8}$ The relative errors were $5 \%-10 \%$ and $10 \%-20 \%$ for $\mathrm{Ca}$ and $\mathrm{P}$ elements, respectively. The determined value of the standard solution was used for the calibration of others. The P content in the precipitate $(\mathrm{Sp})$ was calculated using the equation: $\mathrm{Sp}=$ initial concentration $(5.0 \mathrm{mmol} / \mathrm{L})$ - $\mathrm{P}$ in supernatant. The Ca content in the precipitate $(\mathrm{Sc})$ was obtained in a similar way. Besides, we also dissolved the precipitate in $1 \mathrm{~mL}$ of $3 \% \mathrm{HNO}_{3}$ and determined the $\mathrm{Ca}$ and $\mathrm{P}$ contents by ICP-OES.

X-Ray Diffraction Measurement. We washed the precipitate samples with anhydrous ethanol and dried them under vacuum in a desiccator. The XRD data of the samples were collected on a D8 VENTURE diffractometer (Bruker, Germany) using $\mathrm{Cu} K \alpha$ radiation $(\lambda=1.5406 \AA$ ), at a scanning speed of $10^{\circ} 2 \theta \mathrm{min}^{-1}$ with the step size of $2 \theta=0.02^{\circ}$.

Calcium K-edge XANES Spectroscopy. We acquired the spectral data in the mode of partial fluorescence yield, on Beamline 4B7A at Beijing Synchrotron Radiation Facility (BSRF), China. ${ }^{23}$ Precipitate samples were separated from the reaction mixture by centrifugation at $3000 \times \mathrm{g}$ for 5 min (TG16-W, Xiangyi Co., Changsha, China). After removing the upper supernatant, we took the slurry in the lower part of the centrifuge tube and place it in the sample cell. Then we started the data acquisition within $10 \mathrm{~min}$. The scanning range was $4000-4150 \mathrm{eV}$, with the minimum step of $0.3 \mathrm{eV}$ and the dwell time of $2 \mathrm{sec}$ per point between $4040-4070 \mathrm{eV}$. A single scan took 
about 15-16 min over the full range. Other experimental settings and conditions were as previously described. ${ }^{8}$ We converted the raw data to normalized spectra using the software Athena. ${ }^{24}$

\section{RESULTS AND DISCUSSION}

To determine the quantitative relation between the precipitate and solution composition, we collected pseudo-equilibrium data from the five reaction systems with a fixed phosphate concentration and varied calcium concentrations. Shown in Figure 1 are the typical free-drift curves of $\mathrm{pH}$ and free $\mathrm{Ca}^{2+}$ ions. Upon mixing the phosphate and calcium solutions, the reaction proceeded through an induction period, followed by a rapid change that completed in about 10 minutes. At scheduled time-points, we collected samples and determined the solution compositions and the quantities of the precipitate samples. Notably, a peak or shoulder was present at the end of the induction period. Similar observations have been reported previously by $\mathrm{us}^{25}$ and other investigators $^{21}$. A higher stirring rate made the peak (or shoulder) present sooner.
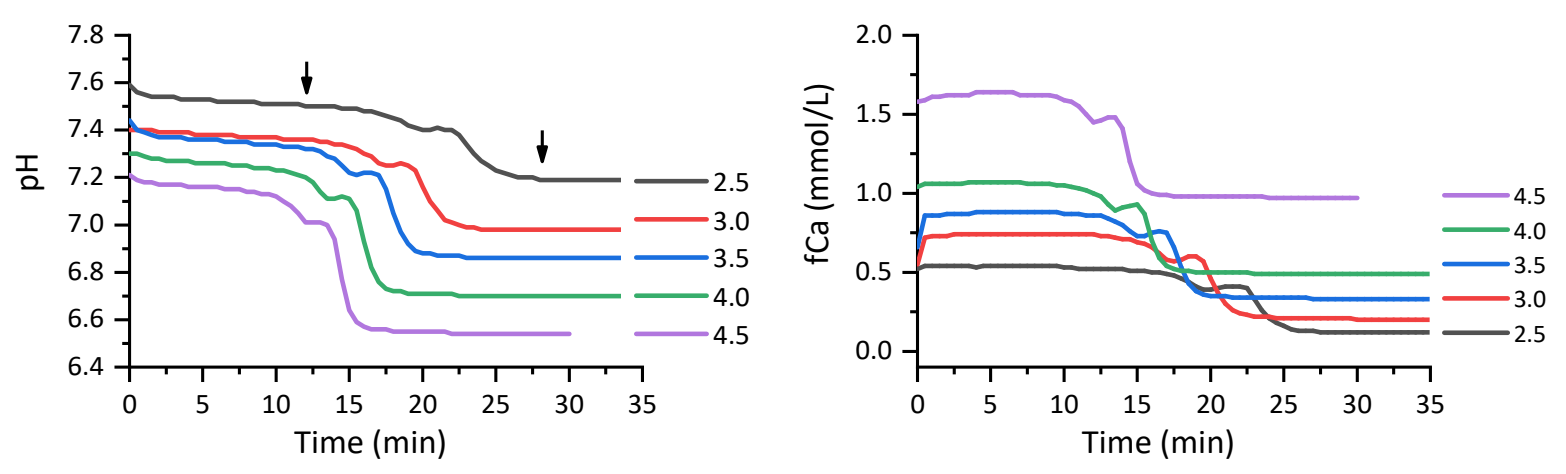

Figure 1. Representative free drift curves of solution $\mathrm{pH}$ and free calcium concentration. Arrows indicate the middle of the induction period (Ind) and the completion of the rapid change period (CRC). Numbers show the initial concentrations of calcium in the five reaction systems: $[\mathrm{Pi}]=$ $5.00 \mathrm{mmol} / \mathrm{L}$ and $\left[\mathrm{Ca}^{2+}\right]=2.50,3.00,3.50,4.00,4.50 \mathrm{mmol} / \mathrm{L}$. 
Eq 1 represents the chemical reaction at the early stage of calcium phosphate crystallization. On the left side, the phosphate (Pi) in solution were mainly $\mathrm{H}_{2} \mathrm{PO}_{4}{ }^{-}$and $\mathrm{HPO}_{4}{ }^{2-}$ at the near neutral $\mathrm{pH}$. Accordingly, we express Pi as the sum of its constituents (eq 2a), where $x$ and $(1-x)$ are the portions of $\mathrm{H}_{2} \mathrm{PO}_{4}{ }^{-}$and $\mathrm{HPO}_{4}{ }^{2-}$, respectively. On the right side, the precipitate has a $\mathrm{Ca} / \mathrm{P}$ molar ratio of $\mathrm{r}$, with the phosphate being in the forms of $\mathrm{HPO}_{4}{ }^{2-}$ and $\mathrm{PO}_{4}{ }^{3-}$. Likewise, we express $\mathrm{Pi}$ in the precipitate with eq $2 \mathrm{~b}$, where $\mathrm{y}$ and $(1-\mathrm{y})$ are the portions of $\mathrm{PO}_{4}{ }^{3-}$ and $\mathrm{HPO}_{4}{ }^{2-}$, respectively. Substituting eq. 2 into eq 1 gives eq 3 , where $(x+y) \mathrm{mH}^{+}$is added for mass balance. Eq 4 is derived from the charge balance of the precipitate, which correlates y and $r$. For example, if $m=4$ and $r=$ 1.25 , one obtains $\mathrm{y}=0.5$. Thus the formula of the precipitate is $\mathrm{Ca}_{5}\left(\mathrm{HPO}_{4}\right)_{2}\left(\mathrm{PO}_{4}\right)_{2}$, equivalent to $2 \mathrm{Ca}\left(\mathrm{HPO}_{4}\right) \cdot \mathrm{Ca}_{3}\left(\mathrm{PO}_{4}\right)_{2}$ in chemical composition.

$$
\begin{aligned}
& \mathrm{rm} \mathrm{Ca}^{2+}+\mathrm{m} \mathrm{Pi}=\mathrm{Ca}_{\mathrm{rm}} \mathrm{Pi}_{\mathrm{m}} \\
& \mathrm{Pi}(\text { in solution })=(1-\mathrm{x}) \cdot \mathrm{HPO}_{4}^{2-}+\mathrm{x} \cdot \mathrm{H}_{2} \mathrm{PO}_{4}^{-} \\
& \mathrm{Pi}(\text { in precipitate })=(1-\mathrm{y}) \cdot \mathrm{HPO}_{4}^{2-}+\mathrm{y} \cdot \mathrm{PO}_{4}^{3-} \\
& \mathrm{rmCa}^{2+}+(1-\mathrm{x}) \mathrm{mHPO}_{4}^{2-}+\mathrm{xmH}_{2} \mathrm{PO}_{4}^{-}=\mathrm{Ca}_{\mathrm{rm}}\left(\mathrm{HPO}_{4}\right)_{(1-\mathrm{y}) \mathrm{m}}\left(\mathrm{PO}_{4}\right)_{\mathrm{ym}}+(\mathrm{x}+\mathrm{y}) \mathrm{mH}^{+} \\
& 2 \mathrm{rm}=2(1-\mathrm{y}) \mathrm{m}+3 \mathrm{ym} \\
& \mathrm{y}=2(\mathrm{r}-1)
\end{aligned}
$$

Eq 5 is the equilibrium equation relevant to eq 3 , expressed in terms of the dissociation constant $K_{\mathrm{d}}$. To make the constant dimensionless, we use the "relative concentration" (i.e. [concentration in $\mathrm{mol} / \mathrm{L}] / \mathrm{c}^{\Theta}$, where $\mathrm{c}^{\Theta}=1 \mathrm{~mol} / \mathrm{L}$ is the standard concentration) for the terms on the right side of eq 5. Because the concentration of the precipitate $\mathrm{Ca}_{\mathrm{rm}}\left(\mathrm{HPO}_{4}\right)_{(1-\mathrm{y}) \mathrm{m}}\left(\mathrm{PO}_{4}\right)_{\mathrm{ym}}$ is unknown before 
determining the value of $\mathrm{m}$, we express it in the phosphorus content $\left(\mathrm{S}_{\mathrm{P}}\right.$, eq 6a). Alternatively, it can be represented by its calcium content $\left(\mathrm{S}_{\mathrm{Ca}}\right.$, eq $\left.6 \mathrm{~b}\right)$. Here, $\mathrm{m}$ denotes the apparent number of phosphate anions in the formula of the precipitate (eq 1). If the reactions proceeded to roughly the same extent at the sample-collection time, the composition and structure of the precipitate samples would be same in all the five systems. Therefore, the parameter $\mathrm{m}$ in eq 5 should be a constant in this case. By introducing eq 6a into eq 5 and rearrangement, we obtain eq 7. Its logarithmic form is eq 8 , in which the quantity of precipitate is linearly correlated with the solution composition.

$$
\begin{aligned}
& K_{\mathrm{d}}=\frac{[\mathrm{Ca}]^{\mathrm{rm}}\left[\mathrm{HPO}_{4}\right]^{(1-\mathrm{x}) \mathrm{m}}\left[\mathrm{H}_{2} \mathrm{PO}_{4}\right]^{] \mathrm{m}}}{[\mathrm{H}]^{(\mathrm{x}+\mathrm{y}) \mathrm{m}}\left[\mathrm{Ca}_{\mathrm{rm}}\left(\mathrm{HPO}_{4}\right)_{(1-\mathrm{y}) \mathrm{m}}\left(\mathrm{PO}_{4}\right)_{\mathrm{ym}}\right]} \\
& {\left[\mathrm{Ca}_{\mathrm{rm}}\left(\mathrm{HPO}_{4}\right)_{(1-\mathrm{y}) \mathrm{m}}\left(\mathrm{PO}_{4}\right)_{\mathrm{ym}}\right]=\mathrm{Sp}_{\mathrm{P}} / \mathrm{m}} \\
& {\left[\mathrm{Ca}_{\mathrm{rm}}\left(\mathrm{HPO}_{4}\right)_{(1-\mathrm{y}) \mathrm{m}}\left(\mathrm{PO}_{4}\right)_{\mathrm{ym}}\right]=\mathrm{SCa}_{\mathrm{C}} /(\mathrm{rm})} \\
& \mathrm{S}_{\mathrm{p}}=\frac{[\mathrm{Ca}]^{\mathrm{rm}}\left[\mathrm{HPO}_{4}\right]^{(1-\mathrm{x}) \mathrm{m}}\left[\mathrm{H}_{2} \mathrm{PO}_{4}\right]^{\mathrm{xm}}}{[\mathrm{H}]^{(\mathrm{x}+\mathrm{y}) \mathrm{m}}} \cdot \frac{1}{\frac{K_{\mathrm{d}}}{\mathrm{m}}} \\
& \operatorname{LnS}_{\mathrm{p}}=\mathrm{m} \cdot \operatorname{Ln}\left\{\frac{[\mathrm{Ca}]^{\mathrm{r}}\left[\mathrm{HPO}_{4}\right]^{(1-\mathrm{x})}\left[\mathrm{H}_{2} \mathrm{PO}_{4}\right]^{\mathrm{x}}}{[\mathrm{H}]^{(\mathrm{x}+\mathrm{y})}}\right\}-\operatorname{Ln}\left(\frac{K_{\mathrm{d}}}{\mathrm{m}}\right)
\end{aligned}
$$

Before using eq 8 to correlate the pseudo-equilibrium data, we must determine the concentrations of $\mathrm{HPO}_{4}{ }^{2-}$ and $\mathrm{H}_{2} \mathrm{PO}_{4}{ }^{-}$. First, we subtract the experimentally measured fCa from the total calcium in solution (tLCa), obtaining the concentration of the complexed calcium (cCa, eq 9). Then, by assuming that the complexed phosphate (cPi) equals cCa (eq 9) and subtracting cPi from the total phosphate in solution (tLPi), we get the unbound phosphate $\left(\mathrm{HPO}_{4}{ }^{2-}+\mathrm{H}_{2} \mathrm{PO}_{4}{ }^{-}\right.$, eq 10). Finally, we determined the respective concentrations of $\mathrm{HPO}_{4}{ }^{2-}$ and $\mathrm{H}_{2} \mathrm{PO}_{4}^{-}$from the sum of them and the measured solution $\mathrm{pH}$, using the ionization constant $K_{\mathrm{a} 2}=10^{-7.21} .^{26}$ 
In these equations, ion charges are omitted for clarity. The square brackets denote (pseudo)equilibrium concentrations. Since the solutions were at $\mathrm{mmol} / \mathrm{L}$ or lower in the present study, the concentrations of calcium and phosphate are assumed to be equal to the respective activities.

$$
\begin{aligned}
& \mathrm{cPi} \approx \mathrm{cCa}=\mathrm{tLCa}-\mathrm{fCa} \\
& {\left[\mathrm{HPO}_{4}{ }^{2-}\right]+\left[\mathrm{H}_{2} \mathrm{PO}_{4}^{-}\right]=\mathrm{tLPi}-\mathrm{cPi}}
\end{aligned}
$$

Now we plot $\mathrm{LnS}_{\mathrm{p}}$ against $\operatorname{Ln}($ I.P.) according to eq 8, where I.P. stands for the "ionic concentration product" $\frac{[\mathrm{Ca}]^{\mathrm{r}}\left[\mathrm{HPO}_{4}\right]^{(1-\mathrm{x})}\left[\mathrm{H}_{2} \mathrm{PO}_{4}\right]^{\mathrm{x}}}{[\mathrm{H}]^{(\mathrm{x}+\mathrm{y})}}$. As shown in Figure 2, the linearity is indeed present, except for the data from the last reaction system (with the initial concentrations $[\mathrm{Pi}]=5.00$ $\mathrm{mmol} / \mathrm{L}$ and $\left[\mathrm{Ca}^{2+}\right]=4.50 \mathrm{mmol} / \mathrm{L}$ ). Before going further to discuss these results, we make some comments on the factors that could reduce the linearity. (1) At the sample-collecting time, the different systems did not proceed to "the same extent of reaction". In the last reaction system, the extent of reaction was significantly higher than others. Oppositely, lower extents of reaction were observed in $\mathrm{CRC}$ (Figure 2a) and $1 \mathrm{H}$ (Figure $2 \mathrm{~b}$ ) for the data from the first reaction system ([Pi] $=5.00 \mathrm{mmol} / \mathrm{L}$ and $\left[\mathrm{Ca}^{2+}\right]=2.50 \mathrm{mmol} / \mathrm{L}$ ). (2) The precipitate was not pure; rather, it was likely a mixture of substances. Whereas the $\operatorname{LnS}_{\mathrm{p}}$ vs $\operatorname{Ln}$ (I.P.) plot (Figure 2) should ideally be applied to the reaction system in which the precipitate is a pure substance. It deserves a systematic study to separate and characterize all kinds of substances in the precipitate, and make such a plot for each pure substance. 


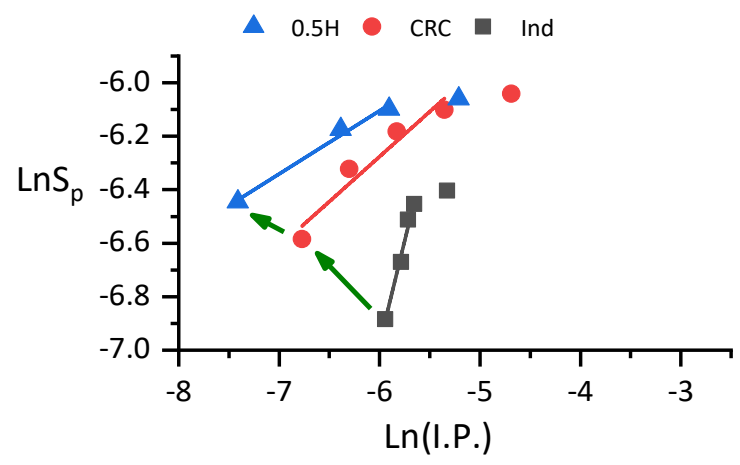

a

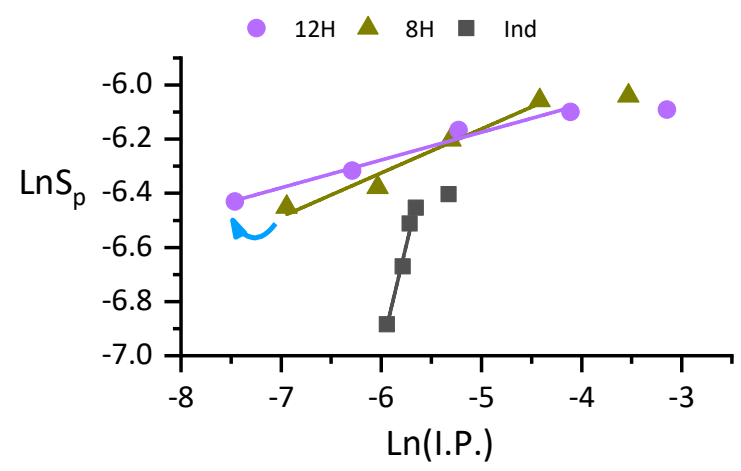

$\mathrm{c}$

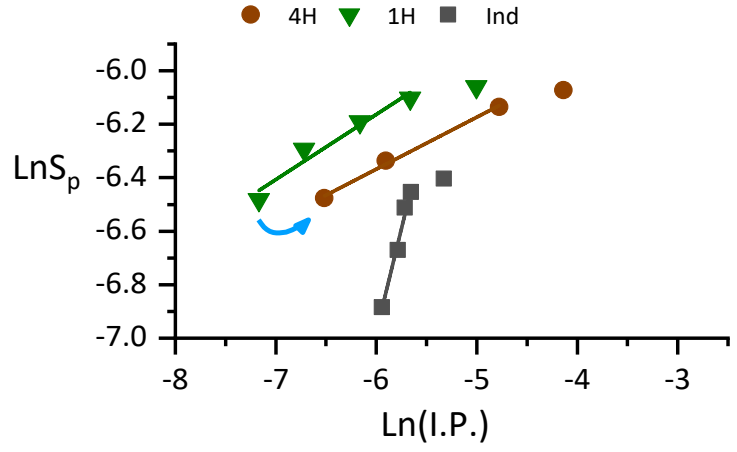

b

Figure 2. Correlation between the solution composition and the quantity of calcium phosphate precipitate in pseudo-equilibrium. Data were collected at the scheduled time-points and plotted according to eq 8, where $S_{P}$ and I.P. stand for the $\mathrm{P}$ content of the precipitate and the "ionic concentration product" $\frac{[\mathrm{Ca}]^{\mathrm{r}}\left[\mathrm{HPO}_{4}\right]^{(1-\mathrm{x})}\left[\mathrm{H}_{2} \mathrm{PO}_{4}\right]^{\mathrm{x}}}{[\mathrm{H}]^{(\mathrm{x}+\mathrm{y})}}$, respectively. Arrows indicate the data sequence. In order to show the differences in curve position, we keep the abscissa and ordinate scales unchanged and display the induction period data (Ind) as a reference in all the three figures. From left to right, each of the five points in a set of data were from a reaction system of the series with the initial concentrations: $[\mathrm{Pi}]=5.00 \mathrm{mmol} / \mathrm{L},\left[\mathrm{Ca}^{2+}\right]=2.50,3.00,3.50,4.00,4.50 \mathrm{mmol} / \mathrm{L}$, respectively. 
Linear curve-fitting was performed to a set of data, excluding the last one. The data of $2 \mathrm{H}$ are close to those of $1 \mathrm{H}$ and omitted for clarity.

Two features are present in the plots in Figure 2. First, the slope of Ind is significantly steeper than those of others, and the slope decreases with time. Second, the direction of the sequential change in curve position reverses with time (Figures $2 \mathrm{a}$ and $2 \mathrm{~b}$ ). The positions of Ind and CRC exhibit a shift toward the top left, indicating more precipitate and lower ion concentrations in solution. Differently, the positions of $1 \mathrm{H}$ and $4 \mathrm{H}$ display a rightward shift. The slope of $12 \mathrm{H}$ is less steep than that of $8 \mathrm{H}$, showing a higher extent of reaction (Figure 2c). It is noteworthy that, in addition to the concentrations of calcium and phosphate, the $\mathrm{Ca} / \mathrm{P}$ ratio $(\mathrm{r})$ of the precipitate in the exponential term has a dramatic impact on the magnitude of Ln(I.P.).

From these plots we obtain the values of slope $(\mathrm{m})$ and intercept, and listed them in Table 1 along with the derived parameters. The parameter $m$ is basically the apparent number of phosphate anions in a structural unit of the precipitate. With the calcium number being $r \times m$ (where $r$ is the $\mathrm{Ca} / \mathrm{P}$ molar ratio), $\mathrm{Ca}_{\mathrm{rm}} \mathrm{Pi}_{\mathrm{m}}$ (Column 5 from left, Table 1) represents the ion pairs composing the effective fraction of a structural unit in a precipitate particle. Here, by "effective" we mean that this fraction was actually involved in the pseudo-equilibrium with the solution composition and may not contain the whole structural unit. 
Table 1. Parameters relevant to the structural unit of the precipitates at various stages of reaction

\begin{tabular}{cccccccccc}
\hline Time* & $\mathbf{m}^{\dagger}$ & $\mathbf{r}_{\text {av }}$ & $\mathbf{r}_{\mathbf{a v}} \mathbf{m}$ & $\mathbf{C a}_{\mathbf{r m}} \mathbf{P i}_{\mathbf{m}}{ }^{*}$ & $\mathbf{u}^{\ddagger}$ & $\mathbf{C a}_{\mathbf{r m u}} \mathbf{P i}_{\mathbf{m u}}{ }^{*}$ & Intercept & $\boldsymbol{K}_{\mathbf{d}}$ & $\mathbf{1} / \boldsymbol{K}_{\mathbf{d}}$ \\
\hline Ind & $1.54 \pm 0.12$ & 1.27 & 1.956 & $\mathrm{Ca}_{1.956} \mathrm{Pi}_{1.54}$ & 2.6 & $\mathrm{Ca}_{5}\left(\mathrm{HPO}_{4}\right)_{2}\left(\mathrm{PO}_{4}\right)_{2}$ & $2.28 \pm 0.71$ & 0.158 & 6.35 \\
\hline $\mathbf{C R C}$ & $0.336 \pm 0.061$ & 1.33 & 0.447 & $\mathrm{Ca}_{0.447} \mathrm{Pi}_{0.336}$ & 9 & $\mathrm{Ca}_{4}\left(\mathrm{HPO}_{4}\right)\left(\mathrm{PO}_{4}\right)_{2}$ & $-4.26 \pm 0.37$ & 23.8 & 0.0420 \\
\hline $\mathbf{0 . 5 H}$ & $0.236 \pm 0.026$ & 1.31 & 0.309 & $\mathrm{Ca}_{0.309} \mathrm{Pi}_{0.236}$ & 13 & $\mathrm{Ca}_{4}\left(\mathrm{HPO}_{4}\right)\left(\mathrm{PO}_{4}\right)_{2}$ & $-4.69 \pm 0.17$ & 25.7 & 0.0389 \\
\hline $\mathbf{1 H}$ & $0.244 \pm 0.038$ & 1.32 & 0.322 & $\mathrm{Ca}_{0.322} \mathrm{Pi}_{0.244}$ & 12.5 & $\mathrm{Ca}_{4}\left(\mathrm{HPO}_{4}\right)\left(\mathrm{PO}_{4}\right)_{2}$ & $-4.70 \pm 0.24$ & 26.8 & 0.0373 \\
\hline $\mathbf{2 H}$ & $0.223 \pm 0.030$ & 1.33 & 0.297 & $\mathrm{Ca}_{0.297} \mathrm{Pi}_{0.223}$ & 13.5 & $\mathrm{Ca}_{4}\left(\mathrm{HPO}_{4}\right)\left(\mathrm{PO}_{4}\right)_{2}$ & $-4.86 \pm 0.19$ & 28.8 & 0.0348 \\
\hline $\mathbf{4 H}$ & $0.194 \pm 0.013$ & 1.36 & 0.264 & $\mathrm{Ca}_{0.264} \mathrm{Pi}_{0.194}$ & 15.5 & $\mathrm{Ca}_{4}\left(\mathrm{HPO}_{4}\right)\left(\mathrm{PO}_{4}\right)_{2}$ & $-5.20 \pm 0.077$ & 35.2 & 0.0284 \\
\hline $\mathbf{8 H}$ & $0.162 \pm 0.022$ & 1.38 & 0.224 & $\mathrm{Ca}_{0.224} \mathrm{Pi}_{0.162}$ & 31 & $\mathrm{Ca}_{7}\left(\mathrm{HPO}_{4}\right)\left(\mathrm{PO}_{4}\right)_{4}$ & $-5.35 \pm 0.12$ & 34.1 & 0.0293 \\
\hline $\mathbf{1 2 H}$ & $0.103 \pm 0.011$ & 1.39 & 0.143 & $\mathrm{Ca}_{0.143} \mathrm{Pi}_{0.103}$ & 49 & $\mathrm{Ca}_{7}\left(\mathrm{HPO}_{4}\right)\left(\mathrm{PO}_{4}\right)_{4}$ & $-5.66 \pm 0.063$ & 29.6 & 0.0338 \\
\hline
\end{tabular}

* Ind-induction period. CRC-completion of rapid change. Numbers indicate the time (in hour) after CRC.

$\dagger$ Values are from the slope in the $\ln \left(\mathrm{S}_{\mathrm{P}}\right) \mathrm{vs}$. $\ln (\mathrm{I} . \mathrm{P}$.) plots according to eq 8.

\# The effective fraction of a structural unit in a particle. Where Pi stands for $\left(\mathrm{HPO}_{4}{ }^{2-}+\mathrm{PO}_{4}{ }^{3-}\right)$.

$\$$ Multiplied by a constant $u$, the numbers of calcium and phosphate in the effective fraction of a structural unit are converted to integers with a minimum ratio.

Conventionally, chemists use integers $\mathrm{m}$ and $\mathrm{rm}$ in expressing the formula of the calcium phosphate precipitate. In the present study we determined the value of m experimentally. As shown in Table 1, the precipitate in the induction period is the only one with a value of $m>1$, indicating distinct difference in the structure with those in other time-points. Because the $\mathrm{Ca} / \mathrm{P}$ molar ratio of the precipitate is close to unity in the induction period, the composing cluster could initially be $\mathrm{CaHPO}_{4}$ (a simplified form of $\left[\mathrm{Ca}\left(\mathrm{H}_{2} \mathrm{O}\right)_{4}\left(\eta^{2}-\mathrm{HPO}_{4}{ }^{2-}\right)\right]^{2+}$, where $\eta^{2}$ indicates the bidentate mode of coordination), rather than the previously proposed $\mathrm{Ca}_{9}\left(\mathrm{PO}_{4}\right)_{6}{ }^{5}$ At the completion of the rapid change (CRC) period, the value of $m$ dropped abruptly to less than one-fourth of that in the induction period (Ind), and gradually decreased since then. For the precipitate at $12 \mathrm{hr}$ after CRC 
$(12 \mathrm{H})$, the value of $\mathrm{m}$ was as low as 0.103 . Indeed, with the increase in crystallinity as indicated in the XRD patterns (Figure 3), only a fraction of the structural unit in a precipitate particle was in contact with the solution.

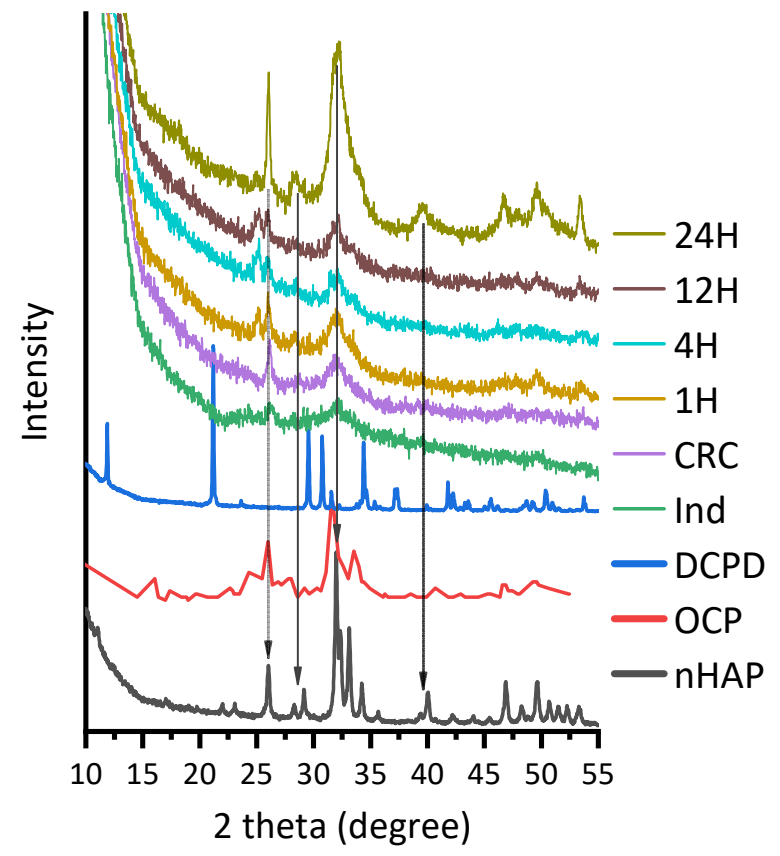

Figure 3. X-ray diffraction patterns of the precipitate samples at various time-points. Hydroxyapatite nanopowder (nHAP), octacalcium phosphate (OCP, powder diffraction file card 26-1056), and dicalcium phosphate dihydrate (DCPD) are included for reference. Initial concentrations: $[\mathrm{Pi}]=4.00 \mathrm{mmol} / \mathrm{L},\left[\mathrm{Ca}^{2+}\right]=4.00 \mathrm{mmol} / \mathrm{L}$.

The dissociation constant $K_{\mathrm{d}}$ is another parameter derived from the plots in Figure 2. Its reciprocal $\left(1 / K_{\mathrm{d}}\right)$ is the corresponding formation constant $\left(K_{\mathrm{f}}\right)$. Judged on the magnitude of $K_{\mathrm{d}}$, the reaction process has three stages. Stage 1 is the induction period (Ind), during which ACP emerged. Although Posner's cluster ${ }^{5,6}$ and other kinds of clusters ${ }^{10}$ have been proposed to be present in solution and to aggregate into ACP, smaller and structurally simpler clusters (such as $\mathrm{CaHPO}_{4}, \mathrm{~K}$ 
$=681^{27}$ ) are more readily to form with higher concentration. For small clusters, aggregation could be more competitive than chemical combination in view of activation energy. In Figure 4a, the spectrum Ind shows a shifted main peak toward the lower energy, an intensified pre-edge peak around $4043 \mathrm{eV}$, and the emergence of the shoulder at $4048 \mathrm{eV}$ (using fCa as the reference). All these spectral features are consistent with those of $\left[\mathrm{Ca}\left(\mathrm{H}_{2} \mathrm{O}\right)_{4}\left(\eta^{2}-\mathrm{HPO}_{4}{ }^{2-}\right)\right]^{2+}$ (an aquated form of $\left.\mathrm{CaHPO}_{4}\right),{ }^{28}$ indicating the presence of the small clusters as the main constituent of the initial ACP. The weak inter-cluster interaction in ACP is consistent with the value of $\mathrm{m}(>1)$. This value would significantly decrease as a crystalline phase emerges. By the way, the contribution of $\mathrm{CaH}_{2} \mathrm{PO}_{4}{ }^{+}$is minor, owing to its smaller formation constant $\left(K=31.9^{27}\right)$. As to the $\mathrm{PO}_{4}{ }^{3-}$ anions in ACP, they derived from the deprotonation of coordinated $\mathrm{HPO}_{4}{ }^{2-}$, rather than directly from the $\mathrm{pH}$ neutral solution. ${ }^{29}$ The $\mathrm{PO}_{4}{ }^{3-}$-containing clusters and crystalline domains successively developed via the aggregation-facilitated cross-linking. Because these less soluble substances were produced in the interior of ACP particles, ${ }^{25}$ they were not readily reachable to the solution. Therefore, it was the substance on the surface of ACP particles that was actually involved in the pseudo-equilibrium with the solution composition, and the dissociation constant $K_{\mathrm{d}}$ in Stage 1 describes the quantitative relation between them. With the expansion of the crystalline domains and the consumption of the surrounding material, the ACP particles eventually collapsed, releasing the previously trapped $\mathrm{H}_{3} \mathrm{O}^{+}$and/or $\mathrm{H}_{2} \mathrm{PO}_{4}^{-}$ions. ${ }^{25}$ The dropping $\mathrm{pH}$ caused the dissolution of the remained ACP, retarding the further drop in $\mathrm{pH}$. The latter event was indicated by the small peak or shoulder at the end of the induction period in Figure 1. 


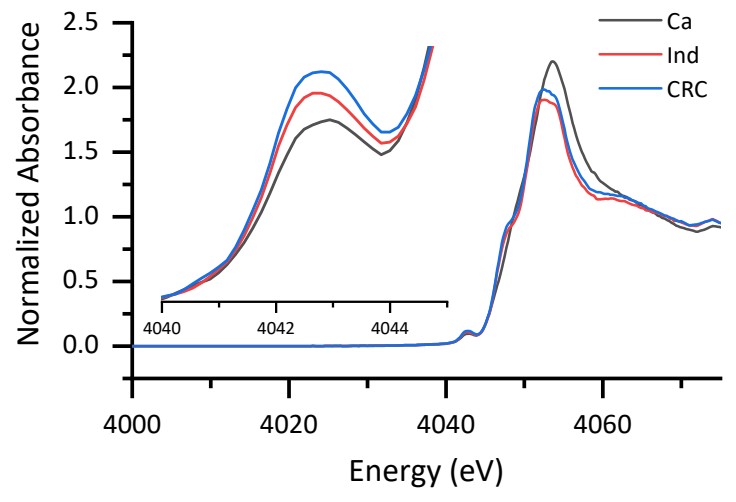

a

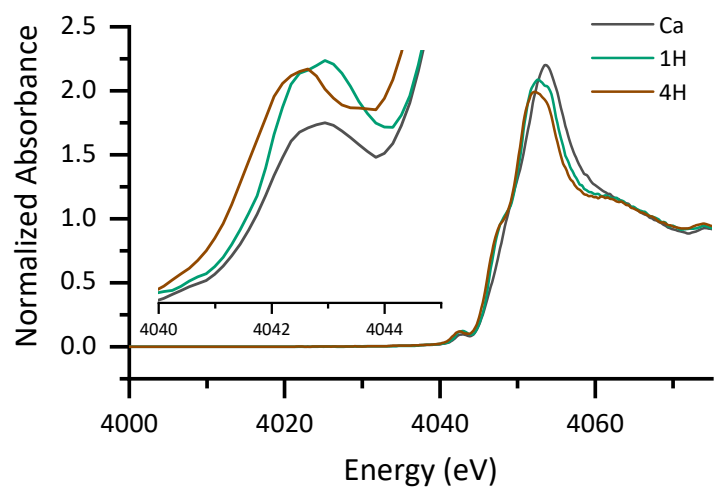

b

Figure 4. Normalized $\mathrm{Ca} K$-edge XANES spectra of wet precipitate at various time-points. Insets show the magnified pre-edge peaks. Initial concentrations: $[\mathrm{Pi}]=4.00 \mathrm{mmol} / \mathrm{L},\left[\mathrm{Ca}^{2+}\right]=4.00$ $\mathrm{mmol} / \mathrm{L}$. The spectrum $\mathrm{Ca}$ (Black), included in both figures as a reference, is the average of 9 traces of the $\mathrm{CaCl}_{2}$ solutions at the concentrations of 50 and $12 \mathrm{mmol} / \mathrm{L}$.

Stage 2 started from the rapid change period and concluded at about 4 hours after CRC. At the end of induction period, the liberated crystallites provided the surface for the nucleation of new crystallites. The averaged $\mathrm{Ca} / \mathrm{P}$ ratio of the precipitate at $\mathrm{CRC}$ shows a local maximum $\left(\mathrm{r}_{\mathrm{av}}\right.$, Table 1). This fact is likely associated with the interfacial phase on the crystals. In the phosphateexcessive solution, the interfacial phase would have a lower $\mathrm{Ca} / \mathrm{P}$ ratio than the crystalline core phase. Because the abrupt change prevented the interfacial phase from reaching pseudoequilibrium with the solution, the HAP core phase would make prominent contribution to the value of $r_{a v}$ at CRC. A steady interfacial phase established afterwards. Its structure and composition were dependent on both the core phase and the solution composition. Octacalcium phosphate $\left[\mathrm{Ca}_{8} \mathrm{H}_{2}\left(\mathrm{PO}_{4}\right)_{6} \cdot 5 \mathrm{H}_{2} \mathrm{O}, \mathrm{OCP}\right]$ is a recognized precursor to HAP. ${ }^{19,21}$ In Figure 3, the XRD patterns of CRC and $1 \mathrm{H}$ show the (002) peak of HAP and OCP at $2 \theta=26.0^{\circ}$, while the precipitates exhibit 
an additional $(2,-2,1)$ peak at $2 \theta=25.87^{\circ}$ from $4 \mathrm{H}$ on, characteristic of OCP. It should be noted that, in either ACP or solution clusters, the calcium and phosphate are bound via weak coordination bond, whereas it is the ionic bond in a crystalline phase. Therefore, an event of bond-type transition must have taken place at the interfacial phase. The release of crystals and the dissolution of ACP at $\mathrm{CRC}$ are consistent with the reduced slope of $\mathrm{m}$ in Figure 2a. By the way, dicalcium phosphate dihydrate $\left(\mathrm{CaHPO}_{4} \cdot 2 \mathrm{H}_{2} \mathrm{O}\right.$, DCPD) has been detected as a precursor to $\mathrm{OCP},{ }^{30}$ but we failed to observe the substance under the present experimental condition.

After CRC it was a crystal ripening process. The precipitate in this stage has previously been recognized as ACP $2 .{ }^{21}$ Indeed, judged from the XRD patterns of $1 \mathrm{H}$ and $4 \mathrm{H}$ (Figure 3), the broadened peaks around $2 \theta=32^{\circ}$ and the higher background at $2 \theta=20-30^{\circ}$ could be indicative of the co-existence of ACP and crystalline HAP. However, the broadening of reflections and the weakening of the scattered intensity may also result from the small size of crystals. ${ }^{31}$ Besides, the gradual change of the slope in Figure 2 indicates the structural similarity between the precipitate samples from CRC on, which are distinct from the ACP in the induction period. If ACP had sustained the significant $\mathrm{pH}$ drop, there must have been stronger coordination bonds between calcium and phosphate, producing the $\mathrm{Ca}\left(\eta^{2}-\mathrm{PO}_{4}{ }^{3-}\right)_{2} \mathrm{~L}_{2}$ type complex with a higher centrosymmetry on the absorber atom. ${ }^{9}$ But the pre-edge peaks in the spectra CRC and $4 \mathrm{H}$ (Figure 4b) are intensified, as compared with that in the spectrum Ind (Figure 4a), indicating a reduced centrosymmetry. Therefore, the spectral information in Figure $4 \mathrm{~b}$ does not support the presence of ACP2. In fact, the spectral features of $\mathrm{CRC}$ and $4 \mathrm{H}$ (Figure $4 \mathrm{~b}$ ) can be explained by the combination of the crystalline core (with prominent pre-edge peak ${ }^{9}$ ) and the heavily hydrated interfacial phase (with strong main peak in the spectrum $\mathrm{Ca}$, Figure 4a). Additionally, if the precipitate had been an amorphous phase with definite composition and structure (as indicated by 
its apparent solubility ${ }^{21}$, the significant difference between the solubilities of ACP and the growing HAP would have made the reaction rate much higher. Hence, the major event in Stage 2 was crystal ripening, rather than the ACP-HAP phase transition. By fluctuation, some crystallites grew larger and caused others to dissolve.

While the value of $\mathrm{m}$ dropped, the change in the value of $K_{\mathrm{d}}$ was relatively small (Table 1 ), indicating the similar structure of the growing and dissolving substances. Such changes in $\mathrm{m}$ and $K_{\mathrm{d}}$ might be characteristic of the ripening process. The parameter m mainly reflects the property of larger crystals, whose value decreases with increasing size. On the other hand, the smaller crystallites were slightly more soluble than the larger ones ${ }^{32}$ and dissolved, maintaining the solution supersaturated to the larger ones. Hence, the constant $K_{\mathrm{d}}$ in Stage 2 shows the capability of lattice ions to leave from the interfacial phase of the dissolving crystals.

Stage 3 covers the rest of the process. With increasing crystallinity (Figure 3), the effective fraction of a structural unit was even smaller in a larger crystal. Hence, the constant $K_{\mathrm{f}}\left(=1 / K_{\mathrm{d}}\right)$ reflects the capability of the interfacial phase to collect lattice ions for the growing crystals.

It is interesting to note that, multiplied by a number $(\mathrm{u})$, the calcium and phosphate numbers in a structural unit could be converted into integers with a minimum ratio (Columns 5 and 4 from right, Table 1). With the number $\mathrm{u}$, we can re-write the general form of the calcium phosphate reaction (eq 1) as eq 11, with the relevant equilibrium constant being eq 12:

$$
\begin{aligned}
& \text { urm Ca }+ \text { um Pi }=\mathrm{Ca}_{r m u} \mathrm{Pi}_{\mathrm{mu}} \\
& \mathrm{rm} \mathrm{Ca}+\mathrm{mPi}=\frac{1}{\mathrm{u}}\left(\mathrm{Ca}_{\mathrm{rm}} \mathrm{Pi}_{\mathrm{m}}\right)_{\mathrm{u}} \\
& K_{\mathrm{d}}=\frac{[\mathrm{Ca}]^{\mathrm{rm}}[\mathrm{Pi}]^{\mathrm{m}}}{\left[\left(\mathrm{Ca}_{\mathrm{rm}} \mathrm{Pi}_{\mathrm{m}}\right)_{\mathrm{u}}\right]^{1 / \mathrm{u}}}
\end{aligned}
$$


The most striking feature of eq 12 is the form of "reaction quotient", rather than "activity product $\left(K_{\mathrm{sp}}\right)$ ", in the case that the reaction system involves an amorphous phase and nanocrystals. Furthermore, the value of $\mathrm{m}$ decreases with increasing crystallinity (Table 1 and Figure 3 ) and, accordingly, it demands a larger value of $u$ to convert the apparent numbers of lattice ions into integers. As a limit case, $\left[\left(\mathrm{Ca}_{\mathrm{rm}} \mathrm{Pi}_{\mathrm{m}}\right)_{\mathrm{u}}\right]^{1 / \mathrm{u}} \rightarrow 1$ as $\mathrm{u} \rightarrow \infty$, and eq 12 converts to eq 13 . On the other hand, $\left[\left(\mathrm{Ca}_{\mathrm{rm}} \mathrm{Pi}_{\mathrm{m}}\right)_{\mathrm{u}}\right]^{1 / \mathrm{u}} \rightarrow\left[\mathrm{Ca}_{\mathrm{rm}} \mathrm{Pi} \mathrm{i}_{\mathrm{m}}\right]$ as $\mathrm{u} \rightarrow 1$, and eq 12 converts to eq 14 . Indeed, eq 12 represents a general form of equilibrium constant equation that relates the two conventional forms, revealing a fundamental relation in chemistry.

$$
\begin{aligned}
& K_{\mathrm{d}}=K_{\mathrm{sp}}=[\mathrm{Ca}]^{\mathrm{rm}}[\mathrm{Pi}]^{\mathrm{m}} \\
& K=\frac{[\mathrm{Ca}]^{\mathrm{rm}}[\mathrm{Pi}]^{\mathrm{m}}}{\left[\mathrm{Ca}_{\mathrm{rm}} \mathrm{Pi}_{\mathrm{m}}\right]}
\end{aligned}
$$

Finally, we use a simple model to illustrate the concept of $\mathrm{m}$ and the correlation between the particle structure and the equilibrium constant equation. In a cubic particle with multiple structural units (Figure 5), the unit number is defined by eq 15 , where $\mathrm{n}$ is a natural number and denotes the dimension of the particle. In the case of $n=2$ (Figure 5a, Table 2), one particle has 8 structural units $\left(u=n^{3}=2^{3}\right)$. Because each cubic unit has 6 faces $\left(m_{0}=6\right)$, the number of the total faces is 48 $\left(M_{1}=6 \times 2^{3}\right.$, eq 16). Among them 24 faces are on the surface $\left(M_{s}=6 \times 2^{2}\right.$, eq 17). Then the average number of the surficial faces per unit $(m)$ can be defined with $m_{0}, M_{s}$ and $M_{t}$ (eq 18a). Alternatively, the parameter $\mathrm{m}$ can be defined by eq $18 \mathrm{~b}$. In either way, the calculated value is 3 ( $2^{\text {nd }}$ column from right, Table 2$)$. In eq 15-18, we use capital letters $\left(M_{t}\right.$ and $\left.M_{s}\right)$ to denote the face numbers in a particle, while for the face numbers in a structural unit we use the lower-case letters $\left(\mathrm{m}\right.$ and $\left.\mathrm{m}_{0}\right)$. 
$\mathrm{u}=\mathrm{n}^{\mathrm{d}}$ (where $\mathrm{d}=3$ for a cubic particle)

$$
\mathrm{M}_{\mathrm{t}}=\mathrm{m}_{0} \times \mathrm{u}=\mathrm{m}_{0} \times \mathrm{n}^{\mathrm{d}}
$$

$\mathrm{M}_{\mathrm{s}}=\mathrm{m}_{0} \times \mathrm{n}^{\mathrm{d}-1}$

$$
\mathrm{m}=\mathrm{m}_{0} \times \frac{\mathrm{M}_{\mathrm{s}}}{\mathrm{M}_{\mathrm{t}}}
$$

$$
\mathrm{m}=\frac{\mathrm{M}_{\mathrm{S}}}{\mathrm{u}}
$$

In the case of $n=3,26$ out of $27\left(=n^{3}\right)$ structural units are on the surface, and only $54\left(M_{s}=6 \times\right.$ $\left.3^{2}\right)$ of $162\left(\mathrm{M}_{\mathrm{t}}=6 \times 3^{3}\right)$ faces are surficial faces (Figure $\left.5 \mathrm{~b}\right)$. Notably, there are four types of units: (1) each of the 8 corner units has 3 surficial faces; (2) each of the 12 edge units has 2 surficial faces (indicated by arrows); (3) each of the 6 units on the cube-face center has 1 surficial face; (4) the unit on the cube center has no surficial face at all. As calculated by eq 18 , the average number of the surficial faces is $m=2\left(2^{\text {nd }}\right.$ column from right, Table 2$)$.

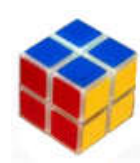

a. $\mathrm{n}=2$

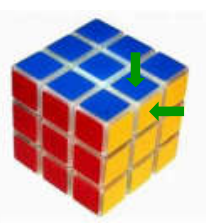

b. $n=3$

Figure 5. A cube model of a multi-unit particle. 
Table 2. Surficial faces and its change with increasing structural unit.

\begin{tabular}{cccccc}
\hline $\mathbf{n}$ & $\mathbf{u}^{*}$ & $\mathbf{M}_{\mathbf{t}}$ & $\mathbf{M}_{\mathbf{s}}$ & $\mathbf{m}^{\#}$ & $\mathbf{m} / \mathbf{m}_{\mathbf{0}}$ \\
\hline $\mathbf{1}$ & 1 & 6 & 6 & 6.00 & $1 / 1$ \\
\hline $\mathbf{2}$ & 8 & 48 & 24 & 3.00 & $1 / 2$ \\
\hline $\mathbf{3}$ & 27 & 162 & 54 & 2.00 & $1 / 3$ \\
\hline $\mathbf{4}$ & 64 & 384 & 96 & 1.50 & $1 / 4$ \\
\hline $\mathbf{5}$ & 125 & 750 & 150 & 1.20 & $1 / 5$ \\
\hline $\mathbf{6}$ & 216 & 1296 & 216 & 1.00 & $1 / 6$ \\
\hline $\mathbf{7}$ & 343 & 2058 & 294 & 0.86 & $1 / 7$ \\
\hline $\mathbf{8}$ & 512 & 3072 & 384 & 0.75 & $1 / 8$ \\
\hline $\mathbf{9}$ & 729 & 4374 & 486 & 0.67 & $1 / 9$ \\
\hline $\mathbf{1 0}$ & $10^{3}$ & $6 \times 10^{3}$ & $6 \times 10^{2}$ & 0.60 & $1 / 10$ \\
\hline $\boldsymbol{\cdots}$ & $\cdots$ & $\cdots$ & $\cdots$ & $\cdots$ & $\cdots$ \\
\hline $\mathbf{6 0}$ & $60^{3}$ & $6 \times 60^{3}$ & $6 \times 60^{2}$ & 0.10 & $1 / 60$ \\
\hline $\boldsymbol{\cdots}$ & $\cdots$ & $\cdots$ & $\cdots$ & $\cdots$ & $\cdots$ \\
\hline $\mathbf{6 0 0}$ & $600^{3}$ & $6 \times 600^{3}$ & $6 \times 600^{2}$ & 0.01 & $1 / 600$ \\
\hline
\end{tabular}

* Number of structural units in a particle. ${ }^{\#}$ The average number of surficial faces per unit.

As listed in Table 2, the value of $\mathrm{m}$ ( or $\mathrm{m} / \mathrm{m}_{0}$ ) decreases with increasing $\mathrm{u}$, reaching to $\mathrm{m} \leq 1$ as $u \geq 6^{3}$. To account for this trend, we re-write eq $18 \mathrm{a}$ as eq 19 . And the latter turns to eq 20 after introducing $n=u^{1 / d}$ (eq 15). Eq 20 correlates the composition $\left(m_{0}\right)$, structure (m and $\left.d\right)$, and size (u) of a multi-unit particle, predicting a decreased $m$ with increasing $u$ (Table 2). Derived from the cube model though, eq 20 seems applicable to the calcium phosphate particles as indicated by the data listed in Table 1. One face in the cube model is equivalent to one pair of the lattice ions (e.g. $\mathrm{Ca}_{\mathrm{r}} \mathrm{Pi}$ ) in a structural unit of a calcium phosphate particle. Eq 21 is a logarithmic form of eq 20, according to which we plot $\ln (\mathrm{u})$ against $\ln (1 / \mathrm{m})$, using the $\mathrm{m}$ and $\mathrm{u}$ values in Table 1 . As shown in Figure 6, a linear relationship is indeed present, excluding the data from the late stage of the reaction $(8 \mathrm{H}$ and $12 \mathrm{H})$. From the linear fit, we obtain $\mathrm{m}_{0}=4.63$ and $\mathrm{d}=0.857$. The values of $\mathrm{u}$, 
$\mathrm{m}_{0}$, and $\mathrm{d}$ could be refined via iteration. Note that the product $\mathrm{m} \times \mathrm{u}\left(3^{\text {rd }}\right.$ column from right, Table 1) gives the initial value of $m_{0}$, under the approximation of $d=1$ (eq 20). The constancy of the two parameters $\left(\mathrm{m}_{0}\right.$ and $\left.\mathrm{d}\right)$ is indicative of the fixed unit structure in the calcium phosphate particles from Ind to $4 \mathrm{H}$. It is worthy of note that the parameters $\mathrm{m}$ and $\mathrm{u}$ are present in both the "particle equation (eq 20)" and the pseudo-equilibrium equation (eq 12), indicating the dependence of the reaction on the structure and size of the particle.

$$
\begin{aligned}
& \frac{m}{m_{0}}=\frac{M_{s}}{M_{t}}=\frac{m_{0} \times n^{d-1}}{m_{0} \times n^{d}}=\frac{1}{n}(\text { where } d=3 \text { for a cubic particle }) \\
& \left(\frac{m}{m_{0}}\right)^{d}=\frac{1}{u} \\
& u\left(\frac{m}{m_{0}}\right)^{d}=1 \\
& L n(u)=d \cdot \ln (1 / m)+d \cdot \ln \left(m_{0}\right)
\end{aligned}
$$

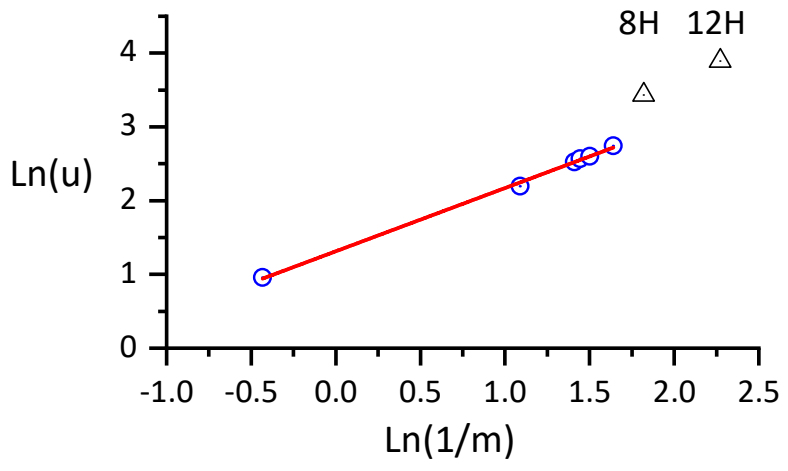

Figure 6. Correlation of the structural parameters of calcium phosphate particles.

Linear fit: Slope $=0.857 \pm 0.017$, Intercept $=1.314 \pm 0.022, \mathrm{R}^{2}=0.998$. 


\section{CONCLUSIONS}

(1) For the crystallization process involving an amorphous phase and/or nanocrystals, the pseudo-equilibrium equation takes the form of $K_{\mathrm{d}}=\frac{[\mathrm{A}]^{\mathrm{rm}}[\mathrm{B}]^{\mathrm{m}}}{\left[\left(\mathrm{A}_{\mathrm{rm}} \mathrm{B}_{\mathrm{m}}\right)_{\mathrm{u}}\right]^{1 / \mathrm{u}}}$ (a generalized form of eq 12). The equation converts to $K=\frac{[\mathrm{A}]^{\mathrm{rm}}[\mathrm{B}]^{\mathrm{m}}}{\left[\mathrm{A}_{\mathrm{rm}} \mathrm{B}_{\mathrm{m}}\right]}(\mathrm{u} \rightarrow 1)$ for a homogeneous system and to $K_{\mathrm{sp}}=$ $[\mathrm{A}]^{\mathrm{rm}}[\mathrm{B}]^{\mathrm{m}}(\mathrm{u} \rightarrow \infty)$ for a conventional precipitation reaction.

(2) The formula $\mathrm{Ca}_{\mathrm{rm}} \mathrm{Pi}_{\mathrm{m}}$ represents the effective fraction of a structural unit $\mathrm{Ca}_{\mathrm{rm}_{0}} \mathrm{Pi}_{\mathrm{m}_{0}}\left(\mathrm{~m}_{0} \geq \mathrm{m}\right)$ in a precipitate particle. The value of $\mathrm{m}$ decreased with increasing crystallinity of the precipitate. Using a cube model, we derived a "particle equation (eq 20)" that correlates the composition $\left(\mathrm{m}_{0}\right)$, structure ( $\mathrm{m}$ and $\mathrm{d})$, and size $(\mathrm{u})$ of a multi-unit particle, revealing the connection between the particle parameters and the equilibrium constant equation.

(3) In the induction period, it was the small and structurally simple clusters, with the formula of $\left[\mathrm{Ca}\left(\mathrm{H}_{2} \mathrm{O}\right)_{4}\left(\eta^{2}-\mathrm{HPO}_{4}{ }^{2-}\right)\right]^{2+}$, that aggregated in solution and brought about the emergence of amorphous calcium phosphate. More complicated clusters and crystalline domains developed successively via the aggregation-facilitated cross-linking inside the particles.

(4) In the ripening process, the dissolved substance is smaller crystals, which has previously been referred to as "Type 2 amorphous calcium phosphate".

\section{AUTHOR INFORMATION}

\section{Corresponding Author}


* ORCID iD: 0000-0003-4589-0118. Fax: 86-10-62015584. Tel.: 86-10-82801539. E-mail: tlzhang@hsc.pku.edu.cn.

\section{Notes}

The authors declare no competing financial interest.

\section{Author Contributions}

H.-X.F., B.-D.G., and T.-L.Z. performed the free drift experiments and collected XANES data. H.X.F., Y.-X.G. and G.W. were responsible for XRD measurement and the determination of calcium and phosphate contents. T.-L.Z. conceived the project, analyzed the data, and wrote the manuscript. All authors have given approval to the final version of the manuscript.

\section{Funding Sources}

This work was jointly funded by Natural Science Foundation of China and Chinese Academy of Sciences (grant number U1632105).

\section{ACKNOWLEDGMENT}

This work was jointly funded by Natural Science Foundation of China and Chinese Academy of Sciences (grant number U1632105), and was supported by the provision of beamtimes by Beijing Synchrotron Radiation Facility at 4B7A. We are grateful to Drs. Fan Li, Xiao-Juan Zhao, Shu-Hu Liu, and Kun Tang at BSRF for their technical assistance with the data collection.

\section{ABBREVIATIONS}

XRD, X-ray diffraction; XANES, X-ray absorption near-edge structure; ACP, amorphous calcium phosphate; DCPD, dicalcium phosphate dihydrate; OCP, octacalcium phosphate; HAP, hydroxyapatite; fCa, free $\mathrm{Ca}^{2+}$; $\mathrm{cCa}$, complexed $\mathrm{Ca}^{2+}$ in solution; tLCa, total calcium in solution 
$(\mathrm{fCa}+\mathrm{cCa}) ; \mathrm{Pi}$, unbound phosphate in solution $\left(\mathrm{HPO}_{4}{ }^{2-}+\mathrm{H}_{2} \mathrm{PO}_{4}{ }^{-}\right)$; $\mathrm{cPi}$, complexed phosphate; tLPi, total phosphate in solution $\left(\mathrm{cPi}+\mathrm{HPO}_{4}{ }^{2-}+\mathrm{H}_{2} \mathrm{PO}_{4}^{-}\right)$.

\section{REFERENCES}

1. E. D. Eanes, I. H. Gillessen and A. S. Posner, Nature, 1965, 208, 365-367.

2. L. Wang and G. H. Nancollas, Chem. Rev. , 2008, 108, 4628-4669.

3. S. V. Dorozhkin, Int. J. Mater. Chem. , 2012, 2, 19-46.

4. C. Combes and C. Rey, Acta Biomater., 2010, 6, 3362-3378.

5. $\quad$ F. Betts and A. S. Posner, Mater. Res. Bull., 1974, 9, 353-360.

6. F. Betts and A. S. Posner, Trans. Am. Crystallogr. Assoc. , 1974, 10, 73-84.

7. V. Čadež, I. Erceg, A. Selmani, D. Domazet Jurašin, S. Šegota, D. Lyons, D. Kralj and M. Sikirić, Crystals, 2018, 8, 254.

8. Q. Zhang, Y. Liu, B.-D. Gou, L. Zheng, Y.-X. Gao and T.-L. Zhang, RSC Advances, 2016, 6, 102710-102723.

9. Q. Zhang, Y. Jiang, B.-D. Gou, J. Huang, Y.-X. Gao, J.-T. Zhao, L. Zheng, Y.-D. Zhao, T.-L. Zhang and K. Wang, Cryst. Growth Des., 2015, 15, 2204-2210.

10. W. J. E. M. Habraken, J. Tao, L. J. Brylka, H. Friedrich, L. Bertinetti, A. S. Schenk, A. Verch, V. Dmitrovic, P. H. H. Bomans, P. M. Frederik, J. Laven, P. van der Schoot, B. Aichmayer, G. de With, J. J. DeYoreo and N. A. J. M. Sommerdijk, Nat. Commun., 2013, 4, 1507.

11. B. Xie, T. J. Halter, B. M. Borah and G. H. Nancollas, Cryst. Growth Des., 2014, 14, 1659-1665.

12. J. Mahamid, A. Sharir, D. Gur, E. Zelzer, L. Addadi and S. Weiner, J. Struc. Biol., 2011, 174, 527-535.

13. A. Akiva, M. Kerschnitzki, I. Pinkas, W. Wagermaier, K. Yaniv, P. Fratzl, L. Addadi and S. Weiner, J. Am. Chem. Soc., 2016, 138, 14481-14487.

14. M. Li, L. Wang, W. Zhang, C. V. Putnis and A. Putnis, Cryst. Growth Des., 2016, 16, 4509-4518.

15. H. Birkedal, in New Perspectives on Mineral Nucleation and Growth: From Solution Precursors to Solid Materials, eds. A. E. S. Van Driessche, M. Kellermeier, L. G. Benning and D. Gebauer, Springer International Publishing, Cham, 2017, DOI: 10.1007/978-3-319-45669-0_10, pp. 199-210.

16. R. Demichelis, N. A. Garcia, P. Raiteri, R. Innocenti Malini, C. L. Freeman, J. H. Harding and J. D. Gale, J. Phys. Chem. B, 2018, 122, 1471-1483.

17. G. Mancardi, U. Terranova and N. H. de Leeuw, Cryst. Growth Des., 2016, 16, $3353-$ 3358.

18. T.-J. Lin and C.-C. Chiu, Phys. Chem. Chem. Phys., 2018, 20, 345-356.

19. J. L. Meyer and E. D. Eanes, Calcif. Tissue Res. , 1978, 25, 59-68.

20. H. E. Lundager Madsen, I. Lopez-Valero and V. Lopez-Acevedo, J. Cryst. Growth, 1986, 75, 429-434.

21. M. R. Christoffersen, J. Christoffersen and W. Kibalczyc, J. Cryst. Growth, 1990, 106, 349-354.

22. C. Holt, E. S. Sørensen and R. A. Clegg, FEBS Journal, 2009, 276, 2308-2323. 
23. L. Zheng, Y. D. Zhao, K. Tang, C. Y. Ma, C. H. Hong, Y. Han, M. Q. Cui and Z. Y. Guo, Spectrochim. Acta, Part B, 2014, 101, 1-5.

24. B. Ravel and M. Newville, J. Synchrotron Radiat., 2005, 12, 537-541.

25. C.-G. Wang, J.-W. Liao, B.-D. Gou, J. Huang, R.-K. Tang, J.-H. Tao, T.-L. Zhang and K. Wang, Cryst. Growth Des. , 2009, 9, 2620-2626.

26. D. R. Lide, CRC Handbook of Chemistry and Physics, CRC Press, 88 edn., 2008.

27. M. S.-A. Johnsson and G. H. Nancollas, Crit. Rev. Oral Biol. Med., 1992, 3, 61-82.

28. B.-D. Gou, Y. Liu, Y.-X. Gao, K. Tang, L. Zheng, Y.-D. Zhao and T.-L. Zhang, J. Struct. Biol., 2019, 205, 41-47.

29. L.-W. Du, S. Bian, B.-D. Gou, Y. Jiang, J. Huang, Y.-X. Gao, Y.-D. Zhao, W. Wen, T.L. Zhang and K. Wang, Cryst. Growth Des., 2013, 13, 3103-3109.

30. O. Borkiewicz, J. Rakovan and C. L. Cahill, Am. Mineral., 2010, 95, 1224-1236.

31. E. I. Suvorova and P. A. Buffat, Crystallogr. Rep., 2001, 46, 722-729.

32. O. Söhnel and F. Grases, Urol. Res., 2011, 39, 429-436. 
For Table of Contents Use Only

\title{
Pseudo-equilibrium equation of calcium phosphate precipitation from aqueous solution
}

\author{
Hong-Xing Fan ${ }^{a, b}$, Bao-Di Gou ${ }^{c}, Y u-X i G^{a}{ }^{a}$, Gang Wu ${ }^{b}$, Tian-Lan Zhang ${ }^{c, *}$
}

* Fax: 86-10-62015584. Tel.: 86-10-82801539. E-mail: tlzhang@hsc.pku.edu.cn.

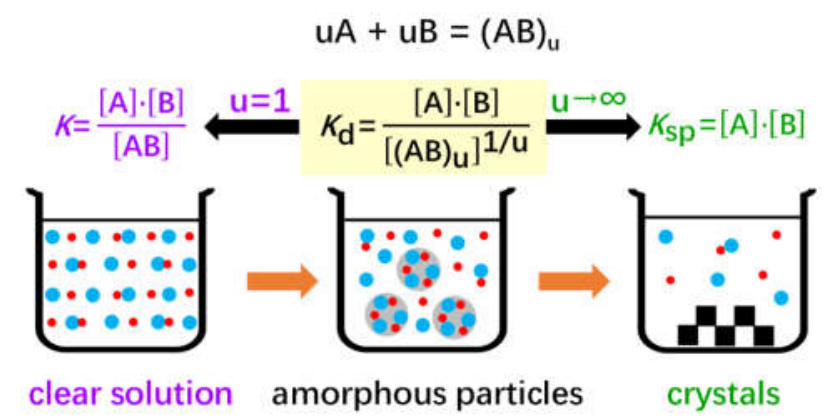

Texture matters. An amorphous phase is present at the early stage of calcium phosphate crystallization. In this case, the equilibrium constant equation takes the general form (middle). It converts to the conventional "reaction quotient" (left) and "solubility product" (right) in two limit cases, respectively. 